DR. TOMI T LAITINEN (Orcid ID : 0000-0003-2771-8955)

Article type : Original

\title{
Childhood socioeconomic disadvantage and risk of fatty liver in adulthood: the
}

\section{Cardiovascular Risk in Young Finns Study}

Tomi T. Laitinen, MD, $\mathrm{PhD}^{1,2}$; Jussi Vahtera, MD, $\mathrm{PhD}^{3}$; Katja Pahkala, $\mathrm{PhD}^{1,2}$; Costan G. Magnussen, $\mathrm{PhD}^{1,4}$; Joel Nuotio, MD, $\mathrm{PhD}^{1}$; Nina Hutri-Kähönen, $\mathrm{MD}, \mathrm{PhD}^{5}$; Mika Kivimäki, FMedSci ; Terho Lehtimäki, MD, $\mathrm{PhD}^{7}$; Eero Jokinen, MD, PhD ${ }^{8}$; Tomi Laitinen, MD, PhD ${ }^{9}$; Päivi Tossavainen, MD, PhD ${ }^{10}$; Jaana Pentti, BSc ${ }^{3,11}$ Jorma S.A.Viikari, MD, $\mathrm{PhD}^{12}$; Markus Juonala, MD, $\mathrm{PhD}^{1,12} ;$ Olli T. Raitakari, MD, $\mathrm{PhD}^{1,13}$

${ }^{11}$ Research Centre of Applied and Preventive Cardiovascular Medicine; University of Turku, Turku, Finland; Centre for Population Health Research, University of Turku and Turku University Hospital, Turku, Finland. ${ }^{2}$ Paavo Nurmi Centre, Sports \& Exercise Medicine Unit, Department of Physical Activity and Health, University of Turku, Turku, Finland. ${ }^{3}$ Department of Public Health, University of Turku and Turku University Hospital, Turku, Finland. ${ }^{4}$ Menzies Institute for Medical Research, University of Tasmania, Hobart, Australia. ${ }^{5}$ Department of Pediatrics, University of Tampere and Tampere University Hospital, Tampere, Finland. ${ }^{6}$ Clinicum, Faculty of Medicine, University of Helsinki, Helsinki, Finland; Department of Epidemiology and Public Health, University College London, London, UK. 'Department of Clinical Chemistry, Fimlab Laboratories and Finnish Cardiovascular Research Center - Tampere, Faculty of Medicine and Life Sciences, University of Tampere, Tampere, Finland. ${ }^{8}$ Department of Pediatric Cardiology, Hospital for Children and Adolescents, University of Helsinki, Helsinki, Finland. ${ }^{9}$ Department of Clinical Physiology and Nuclear Medicine, Kuopio University Hospital and University of Eastern Finland, Kuopio, Finland. ${ }^{10}$ Department of Pediatrics, Oulu University Hospital, PEDEGO Research Unit and MRC Oulu, University of Oulu, Oulu, Finland ${ }^{11}$ Clinicum, Faculty of Medicine, University of Helsinki, Helsinki, Finland. ${ }^{12}$ Department of Medicine, University of Turku and Division of Medicine, Turku

This article has been accepted for publication and undergone full peer review but has not been through the copyediting, typesetting, pagination and proofreading process, which may lead to differences between this version and the Version of Record. Please cite this article as doi: 10.1002/hep.30804

This article is protected by copyright. All rights reserved. 
University Hospital, Turku, Finland. ${ }^{13}$ Department of Clinical Physiology and Nuclear Medicine, University of Turku and Turku University Hospital, Turku, Finland.

\section{Address for correspondence}

Tomi T. Laitinen, Research Centre of Applied and Preventive Cardiovascular Medicine, University of Turku, Kiinamyllynkatu 10, FIN-20520 Turku, Finland. E-mail tomi.laitinen@utu.fi

\section{Sources of Funding}

The Young Finns Study has been financially supported by the Academy of Finland: grants 286284, 134309 (Eye), 126925, 121584, 124282, 129378 (Salve), 117787 (Gendi), and 41071 (Skidi); the Social Insurance Institution of Finland; Competitive State Research Financing of the Expert Responsibility area of Kuopio, Tampere and Turku University Hospitals (grant X51001); Juho Vainio Foundation; Paavo Nurmi Foundation; Finnish Foundation for Cardiovascular Research; Finnish Cultural Foundation; The Sigrid Juselius Foundation; Tampere Tuberculosis Foundation; Emil Aaltonen Foundation; Yrjö Jahnsson Foundation; Signe and Ane Gyllenberg Foundation; Diabetes Research Foundation of Finnish Diabetes Association; and EU Horizon 2020 (grant 755320 for TAXINOMISIS); and European Research Council (grant 742927 for MULTIEPIGEN project); Tampere University Hospital Supporting Foundation. CGM is supported by a National Heart Foundation of Australia Future Leader Fellowship (100849). MK is supported by Helsinki Institute of Life Sciences, the Academy of Finland (311492), NordForsk, and the US National Institute on Aging (R01AG056477).

\section{Acknowledgements}

We thank the teams that collected data at all measurement time points; the persons who participated as both children and adults in this longitudinal study; and biostatisticians Noora Kartiosuo, Irina Lisinen, Johanna Ikonen, Ville Aalto, and Jarno Kankaanranta for data management and statistical advice.

This article is protected by copyright. All rights reserved. 


\section{Conflicts of Interest}

None

\section{ABSTRACT}

Fatty liver is a preventable cause of liver failure, but early risk factors for adulthood fatty liver are poorly understood. We examined the association of childhood socioeconomic disadvantage with adulthood fatty liver and tested adulthood risk factors of fatty liver as possible mediators of this link. The study population comprised 2,042 participants aged 3-18 years at baseline (1980) from the longitudinal Cardiovascular Risk in Young Finns Study. Follow-up with repeated clinical examinations was 31 years. Childhood socioeconomic disadvantage was assessed using data from parents' socioeconomic position and socioeconomic circumstances in participants' residential neighborhoods, categorized as high versus low socioeconomic disadvantage. Fatty liver was determined by ultrasound during the last follow up (2011) at ages 34-49 years. Childhood and adulthood risk factors, including metabolic biomarkers and life-style variables, were assessed in clinical examinations. $18.9 \%$ of the participants had fatty liver in adulthood. High childhood socioeconomic disadvantage was associated with an increased risk of fatty liver (risk ratio[95\% confidence interval] $1.42[1.18-1.70], P=0.0002)$. This association was robust to adjustment for age, sex, and childhood risk factors of fatty liver, including high body mass index, elevated insulin, and low birth weight (1.33[1.09-1.62],P=0.005). High childhood socioeconomic disadvantage was also associated with the development of risk factors of fatty liver in adulthood. Adulthood risk factors linking childhood socioeconomic disadvantage with fatty liver included waist circumference (proportion mediated of the total effect of childhood socioeconomic disadvantage 45\%), body mass index (40\%), systolic blood pressure (29\%), insulin (20\%), physical activity (15\%), triglycerides (14\%), and red meat consumption (7\%). Conclusion: Childhood socioeconomic disadvantage was associated with multiple risk factors of fatty liver and increased likelihood of fatty liver in adulthood. Key Words: Longitudinal study; Hepatic steatosis; Socioeconomic status; Risk factors; Population study 


\section{INTRODUCTION}

Non-alcoholic fatty liver disease (also known as 'fatty liver') is a major public health concern affecting approximately $20 \%$ of people worldwide. ${ }^{1}$ It is the most common cause of chronic liver disease in industrialized countries and is also predicted to become the most common indication for liver transplantation by $2030 .^{2}$ In adults, obesity and metabolic disturbances, such as insulin resistance and dyslipidemia, are associated with increased risk of fatty liver. ${ }^{2}$ In addition, physical inactivity and unhealthy dietary habits have been considered as behavioral risk factors of fatty liver..$^{3-4}$ In addition, we previously identified low birth weight, high insulin, and high BMI in childhood as risk factors for adult fatty liver. ${ }^{5}$

Socioeconomic disparities in morbidity and mortality are major public health problems for industrialized countries. ${ }^{6,7}$ People living in disadvantaged areas generally experience worse health outcomes than those living in more affluent areas, independent of their personal socioeconomic status. ${ }^{8,9}$ Using data from the longitudinal Cardiovascular Risk in Young Finns study, we recently showed that lifetime neighborhood disadvantage was associated with fatty liver in adulthood. ${ }^{10}$ In the present study, we specifically aimed to examine the prospective association of childhood socioeconomic disadvantage (SED) on adult fatty liver. We tested whether childhood SED, characterized by parental and childhood neighborhood SED, is associated with fatty liver measured three decades later in mid-adulthood. In addition, we used mediation analysis ${ }^{11}$ to determine if the association between childhood SED and fatty liver was mediated by known adulthood risk factors of fatty liver.

This article is protected by copyright. All rights reserved. 


\section{METHODS}

\section{Participants}

The Cardiovascular Risk in Young Finns Study is on ongoing multicenter follow-up study to assess risk factors underlying CVD. ${ }^{12}$ The first cross-sectional survey was conducted in 1980, when 3,596 individuals aged 3 to 18 years participated. These participants were randomly chosen from the national register of the study areas in different parts of Finland. Since 1980, several follow-up studies have been conducted. ${ }^{12}$ The latest follow-up survey was performed in 2011, when 2,063 of the original participants attended. In this study, the sample comprised 2,042 participants aged 3-18 years at baseline (1980) who provided data on SED in childhood and liver ultrasound data at the 2011 follow-up, when aged 34-49 years. All participants provided written informed consent, and the study was approved by local ethics committees.

\section{Outcome: Fatty liver}

Fatty liver was measured by ultrasound imaging of the liver performed for 2,042 study participants in 2011 using a validated protocol and Sequoia 512 ultrasound mainframes (Acuson, Mountain View, CA, USA) with 4.0 MHz adult abdominal transducers. ${ }^{13}$ Evaluation of hepatic steatosis was performed according to liver-to-kidney contrast, parenchymal brightness, deep beam attenuation and bright vessel walls. ${ }^{13}$ According to these criteria the presence of hepatic steatosis was assessed visually by a one trained ultrasonographer blinded to participant's characteristics. Participants were categorized into two groups; those with ( $N=385)$ and without $(\mathrm{N}=1,657)$ fatty liver (prevalence of fatty liver $18.9 \%)$. By using national hospital discharge registries, containing data on those discharged from inpatient care in hospitals, we were able to verify that none of the participants had viral or autoimmune causes of fatty liver.

This article is protected by copyright. All rights reserved. 


\section{Childhood socioeconomic disadvantage}

Assessment of childhood SED was based on parental SED and neighborhood SED, i.e. SED of the adult population in the childhood residential neighborhoods. Parental SED was constructed using 3 indicators based the length of the parent's education (in years for the parent with the highest education), mean household income (continuous variable) and unemployment of the parent or parents (yes vs no). Each indicator was standardized (mean=0, SD=1), the only exception was unemployment which was coded as -1 for a history of unemployment and 0 otherwise. The overall score for parental SED was the mean of the 3 indicators, with a higher score indicating higher parental SED ( $N=2041)$. Neighborhood SED was based on the same 3 indicators. Data on neighborhood SED were obtained from the Statistics Finland's grid database. This $250 \times 250$ meter grid national database can provide a neighborhood SED score for all Finnish residents in grids with at least 10 adult residents. The score for each $250 \times 250$ meter grid in Finland is derived from the proportion of adults with a low of educational level, the proportion of home ownership (an indicator of wealth), and the unemployment rate, with each of the 3 variables standardized as z-score, as previously described. ${ }^{10}$ The SED score for each neighborhood is the mean value across all $3 \mathrm{z}$-scores, the national mean being 0 and standard deviation 1 , with a higher score indicating a higher neighborhood SED. To determine the neighborhood SED in this study, the participants' residential history with dates of moves were obtained from the Finnish Population Register Centre. The data was the linked on the residential neighborhoods to the cohort participants' home addresses with dates of moves between 1980 and 2013 using latitude and longitude coordinates. ${ }^{10}$ Neighborhood SED in childhood ( $N=1733)$ was computed by summing up the residential time-weighted cumulative neighborhood SED score in each address from the age of 6 to 21 years. In sensitivity analyses, neighborhood SED was assessed also from the age of 3 to 18 years ( $N=1533)$

Childhood SED was calculated as the mean of parental SED and childhood neighborhood SED and categorized to high $(>0 ; \mathrm{N}=995)$ and low $(<0 ; \mathrm{N}=1047)$ for the analyses. To examine the relative contribution of parental SED and childhood neighborhood SED on the development of fatty liver, we

This article is protected by copyright. All rights reserved. 
also constructed a 4-category variable (high-high [ $\mathrm{N}=482$ ], high-low [ $\mathrm{N}=379]$, low-high [ $\mathrm{N}=258$ ], and lowlow [ $\mathrm{N}=613]$ ) using 0 as a cut-off point for both components of childhood SED.

\section{Childhood risk factors of fatty liver}

BMI, insulin and birth weight have previously been identified as childhood risk factors of adulthood fatty liver in this cohort ${ }^{5}$ and were considered as childhood risk factors in the present study. In the present study, childhood BMI and insulin indicates the baseline level of the variable in 1980. Height and weight were measured and BMI calculated as weight in kilograms divided by height in meters squared. Serum insulin was measured with standard enzymatic methods. Data on birth weight was verified by well-baby clinic records $(N=1,752)$. Low birth weight was defined as birth weight $<10$ th percentile. ${ }^{5}$ The sex-specific cut of points for low birth weight used in the analyses were $<2,850 \mathrm{~g}$ for girls and $<2,900 \mathrm{~g}$ for boys. Information on place of birth (Eastern or Western Finland) was obtained with a questionnaire.

\section{Adulthood risk factors of fatty liver (Possible mediators)}

BMI, waist circumference, insulin, systolic blood pressure, triglycerides, physical activity, smoking, consumption of alcohol, and consumption of red meat, all previously shown as adulthood risk factors of fatty liver in this and other cohorts ${ }^{3-4,13}$, were considered as possible mediators between the association of childhood SED and adulthood fatty liver. Adulthood risk factors of fatty liver (possible mediators) were measured in the adulthood follow-ups in 2001, 2007, and 2011. In the present study, the mediator indicates the mean value of the variable from these three adulthood follow-ups, or daily smoking in any of the adulthood follow-ups. Height and weight were measured, and BMI was calculated as weight in kilograms divided by height in meters squared. Waist circumference was measured midway between iliac crest and the lowest rib at the midaxillary line using a non-stretch plastic covered cloth measuring tape to the nearest $0.1 \mathrm{~cm}$. Blood pressure was measured using a random zero sphygmomanometer in 
adulthood. The average of 3 measurements was used in the analyses. For the determination of serum triglycerides and insulin, venous blood samples were drawn after an overnight fast. These analyses were performed with standard enzymatic methods. Information on physical activity, smoking, dietary habits (red meat consumption), and alcohol consumption was obtained with questionnaires.

\section{Statistical analyses}

Association of childhood and adulthood risk factors of fatty liver, and childhood SED with fatty liver in adulthood were examined using Poisson regression with robust standard errors. The analyses concerning the association of childhood SED and adulthood fatty liver were performed both unadjusted and adjusted with age, sex, place of birth (Eastern or Western Finland), and childhood risk factors for fatty liver (BMI, insulin, and low birth weight). Insulin values were log-transformed for these analyses due to a skewed distribution. Similar analyses were used to examine the association of the 4-category variable for the combinations of high/low parental SED with high/low neighborhood SED in childhood. The results were reported as relative risks (RR) and their $95 \%$ confidence intervals $(\mathrm{Cl})$.

We used counterfactual mediation analysis to examine the effects of childhood SED (exposure) on fatty liver through adulthood risk factors of fatty liver (mediators). The mediation analysis was performed using a SAS macro presented by VanderWeele. ${ }^{11}$ Counterfactual mediation analysis extends from the traditional mediation analysis by allowing for interaction between the exposure and mediator. The causal effects were estimated on the risk ratio scale. The effects were separated into natural direct effects, natural indirect effects, and total effects. The natural direct effect provides risk ratio for the association between childhood SED and fatty liver in a scenario where the level of exposure to the mediator is similar among individuals exposed and non-exposed to high childhood SED. The natural indirect effect refers to the excess risk of fatty liver among those exposed to high childhood SED that is due to their risk status in adulthood. For total effect, both natural direct and indirect effects are taken into account to estimate the risk ratio for association between childhood SED and fatty liver. The

This article is protected by copyright. All rights reserved. 
proportion mediated of the total effect is given as percentages for each mediator. In order to control for the possibility that the potential adulthood mediators began to exert their effect during the period of exposure to childhood SED, we further adjusted the analyses reported in the Supplementary Table 3 for childhood measure of the mediator at the age of 18 years. In case the value was missing, the last available measurement before the age of 18 years was used. The only exceptions were waist and alcohol consumption, for which repeated measurements from childhood were not available. All statistical tests were performed using SAS version 9.4 (SAS institute, Inc, Cary, NC) with statistical significance inferred at a 2-tailed P-value $<0.05$.

\section{RESULTS}

Characteristics of the study participants $(n=2,042)$ are shown in Supplementary Table 1 . The participants were at 3-18 years of age at baseline [mean (SD) 10.8 (5.0) years] and the length of followup was 31 years.

\section{Association between childhood SED and risk of fatty liver in adulthood}

To examine gender differences in the association of childhood SED with adulthood fatty liver, an interaction term of SED*gender was used. No significant SED*gender interaction was detected $(P>0.05)$ indicating that the effect of SED on fatty liver was similar between males and females. Thus, the genders were analyzed combined. High childhood SED was associated with increased risk of fatty liver 31 years later in adulthood (Table 1). This relationship remained significant after adjustment for age, sex, place of birth and childhood risk factors of fatty liver (BMI, insulin, low birth weight). Use of childhood SED as a continuous measure replicated these findings. A 1-SD increase in childhood SED associated with 1.40fold risk of fatty liver in adulthood $(95 \% \mathrm{Cl} 1.19-1.65 ; \mathrm{p}<0.0001)$, and the result remained similar after adjustment for age, sex, place of birth, and childhood risk factors of fatty liver (RR 1.28, 95\% Cl 1.06$1.54, p=0.01)$.

This article is protected by copyright. All rights reserved. 
To examine possible mediators of the association between childhood SED and adulthood fatty liver, we performed mediation analyses (Table 2). In these analyses, the following mediators were identified: adulthood waist circumference (risk ratio [95\% confidence interval] for natural indirect effect 1.12[1.061.18]), BMI (1.10[1.05-1.16]), systolic blood pressure (1.08[1.04-1.13]), triglycerides (1.04[1.01-1.06]), insulin (1.02[1.00-1.04]), physical activity (1.04[1.01-1.08]), and red meat consumption (1.02[1.00-1.04]). The proportions mediated of the total effect of childhood socioeconomic disadvantage were $45 \%$ for waist circumference, $40 \%$ for $\mathrm{BMI}, 29 \%$ for systolic blood pressure, $20 \%$ for insulin, $15 \%$ for physical activity, $14 \%$ for triglycerides, and $7 \%$ for red meat consumption. Alcohol consumption and smoking did not mediate the association between childhood SED and adulthood fatty liver.

The separate effects of parental and neighborhood SED were examined using the 4-category variable for the combinations of low/high parental SED with low/high in childhood. Those with both high parental SED and high childhood neighborhood SED had an increased risk for adulthood fatty liver (Figure 1a). In contrast, the exposure to high parental SED or high childhood neighborhood SED alone was not associated with the risk of fatty liver. The results were similar after adjustment for age, sex, place of birth, and childhood risk factors of fatty liver (BMI, insulin, low birth weight) (Figure 1b).

\section{Sensitivity analyses}

In Supplementary Table 2, Supplementary Table 3, and Supplementary Figure 1, we have repeated the analyses shown in Table 1, Table 2, and Figure 1, respectively, using data on participants with neighborhood SED available from the age of 3 to 18 years. Mediation analyses shown in Supplementary Table 2 were further adjusted for childhood level of the mediator. In all these sensitivity analyses, the results were essentially similar to those shown in the main analyses of this study. 


\section{DISCUSSION}

We found that childhood SED was associated with an increased risk of developing fatty liver three decades later in adulthood. This finding was robust to adjustment for other childhood risk factors of fatty liver. Although adulthood risk factors mediated a significant proportion of the effect of childhood SED on fatty liver, the effect of childhood SED was not entirely explained by the excess risk to develop a poorer risk profile in adulthood. These results suggest that SED in early life is an important determinant of subsequent fatty liver.

In this study, we showed that low childhood SED sets an individual on a risk pathway leading to adverse risk factor profile in adulthood. We found that adult measures of adiposity, triglycerides, insulin, systolic blood pressure, physical activity, and red meat consumption were on the pathway linking childhood SED with fatty liver. All these observed mediators have been previously associated with fatty liver. ${ }^{3-4,6,13-}$ ${ }^{16}$ Adiposity and insulin resistance are considered as key factors in the pathophysiology of fatty liver. ${ }^{6}$ Systolic blood pressure is also associated with fatty liver, but the mechanisms that explain the association that are independent of adiposity or insulin resistance remain unknown. ${ }^{13-16}$ In addition, physical inactivity and unhealthy dietary habits, especially high consumption of red meat, have been considered as behavioral risk factors of fatty liver. ${ }^{3,4}$ In this study, the highest proportions mediated of the total effect of childhood SED were observed for adulthood measures of high waist circumference (45\%), BMI (40\%), and systolic blood pressure (29\%). Importantly, also physical activity and red meat consumption, that are modifiable behavioral risk factors, were observed to mediate the association. Although the proportions mediated of the total effect for these behavioral risk factors were lower than those of e.g. waist circumference, BMI, and systolic blood pressure ( $15 \%$ for physical activity and $7 \%$ for red meat consumption), these data give support to interventions targeting the behavioral risk factors of fatty liver to mitigate the detrimental effect of a socioeconomically disadvantaged early life.

This article is protected by copyright. All rights reserved. 
Several potential mechanisms may underlie the findings observed in this study. We showed that the effect of childhood SED on adulthood fatty liver was not entirely explained by adulthood risk factors of fatty liver. In addition, we were able to take into account the role of known childhood risk factors for adulthood fatty liver and after adjustments for these factors the association between SED and fatty liver remained significant. These findings suggest that differences in childhood risk factors are not the principal pathway linking low childhood SED to adulthood fatty liver. Further, we showed that neither low parental SED nor low neighborhood SED alone was associated with fatty liver suggesting that childhood SED should be considered as a broad concept taking into account both parental and neighborhood exposures. Previously, it has been suggested that parental SED and early family environment contribute to metabolic functioning through pathways of depression, hostility, and poor quality of social contacts. ${ }^{17}$ Characteristics of disadvantaged neighborhoods, such as living near major roads and air pollution, are associated with many chronic diseases. ${ }^{18,19}$ Availability of healthy food outlets and residential walkability have been associated with glycemic control and overweight. ${ }^{20,21}$ In addition, a recent study reported that neighborhood violence is associated with increased levels of physiological and cellular stress markers, such as cortisol, in childhood. ${ }^{22}$

Major strengths of this study include the prospective study design, and the long-term follow-up of the participants who were well characterized both in childhood and adulthood, and the objective highdensity measurement of neighborhood socioeconomic disadvantage in childhood. Our analysis fulfilled the assumptions in counterfactual mediation analyses and support causal inference. ${ }^{23} \mathrm{~A}$ prerequisite for mediation analysis is that exposure (childhood SED) and mediator (risk factors of fatty liver) are correlated, and both are also related to the outcome (fatty liver). The assumption of no unmeasured confounding of the exposure-outcome relationship requires that the exposure temporally precedes the outcome. In addition, the assumption of no unmeasured confounding of the mediator-outcome

This article is protected by copyright. All rights reserved. 
relationship requires that the mediator temporally precedes the outcome. Further, the assumption of no unmeasured exposure-mediator confounding requires that the exposure must precede the mediator. In this study, the results from the mediation analyses remained similar after additional adjustment for childhood measure of the mediator, supporting that the assumption of no unmeasured exposuremediator confounding was fulfilled. Finally, the covariates of mediator-outcome association must be independent from the exposure. This study has also limitations. First, liver biopsy is the criterion standard in detecting fatty liver, because it is the only way to detect inflammation or fibrosis. However, it is invasive and may result in severe complications, inhibiting its use in epidemiological studies of the general population. ${ }^{24}$ Ultrasound imaging has also its limitations: while it provides high specificity, the method has low sensitivity, and thus possibly leads to underestimation of fatty liver. ${ }^{25}$ However, a large meta-analysis concluded that ultrasonography allows for reliable and accurate detection of moderatesevere fatty liver, compared to histology. ${ }^{26}$ In our study, the prevalence of fatty liver was $18.9 \%$, which is comparable with prior findings from Finland and worldwide. ${ }^{1,27}$ Liver ultrasound is also an operatordependent modality. In our study, one trained operator who was masked for participant's clinical characteristics graded all ultrasound images, thus eliminating this potential cause of bias. Because ultrasound imaging is non-invasive, widely accessible, and cost-effective, it is likely a reasonable choice for population-based studies into the etiogenesis of fatty liver. ${ }^{26}$ Second, even though we were able to verify from the national hospital discharge registries that none of the participants had a diagnosis of viral or autoimmune hepatitis, undiagnosed viral or autoimmune causes of chronic hepatitis are a potential limitation in this study. However, prevalence estimates for hepatitis C and hepatitis B in Finland are low, $0.03 \%$ and $0.00 \%$, respectively. ${ }^{28}$ In Sweden and Norway, the neighboring countries of Finland, the prevalence of autoimmune hepatitis has been reported to be $0.01-0.02 \%{ }^{29,30}$ which likely corresponds well to the prevalence of the disease in Finland. Thus, due to the low prevalence of viral or autoimmune hepatitis in Finland, the undiagnosed viral or autoimmune causes of chronic hepatitis among this study population are most likely very rare and should not significantly affect the results of this study. Third, in the counterfactual mediation analysis used by $\mathrm{us}^{11}$, multiple mediators can be examined only separately. Therefore, in case the mediators are correlated, the estimated pathways 
partially overlap and the sum of the proportions mediated of the total effect of childhood socioeconomic disadvantage can exceed $100 \%$. Fourth, because our study cohort was racially homogeneous, the generalizability of our results is limited to European populations. Finally, during an extensive study period in the Cardiovascular Risk in Young Finns Study, it is possible that differential loss to follow-up has occurred. However, the study group has been largely dynamic, with non-participation at one follow-up not precluding participation at a subsequent follow-up. In line, we have previously reported baseline risk factor levels to be essentially similar among participants and non-participants at subsequent follow-ups. ${ }^{31}$ Thus, the present study population is largely representative of the original population.

In summary, high childhood SED was associated with increased risk of fatty liver in adulthood three decades later; this association was independent of childhood risk factors of fatty liver. The excess risk was observed only when both parental SED and neighborhood SED in childhood were high, suggesting that approaches aimed at the prevention of fatty liver should be directed both at the family environment and the living environment of the developing child. Because association of childhood SED and adulthood fatty liver was partially mediated by adulthood clinical and behavioral risk factors of fatty liver, special attention should be paid to these risk factors in individuals with disadvantaged early life.

This article is protected by copyright. All rights reserved. 


\section{Figure legends}

Figure 1. Relative risks and $95 \%$ confidence intervals of fatty liver in adulthood according to parental socioeconomic disadvantage in childhood (parental SED) and neighborhood socioeconomic disadvantage in childhood (neighborhood SED). Parental SED and neighborhood SED were both standardized for age and sex, and categorized to high SED $(>0)$ and low SED $(<0)$ for the analyses. Analyses were unadjusted (Panel A) and adjusted for age, sex, place of birth, and childhood risk factors for fatty liver (body mass index, insulin [log-transformed], low birth weight) (Panel B). Low birth weight was defined as sex-specific $<10$ th percentile $(<2850 \mathrm{~g}$ for girls and $<2900 \mathrm{~g}$ for boys). Dotted line - low parental SED and low neighborhood SED ( $n / N=95 / 613$ in Panel $A$, and $n / N=80 / 539$ in Panel B).

This article is protected by copyright. All rights reserved. 
A)

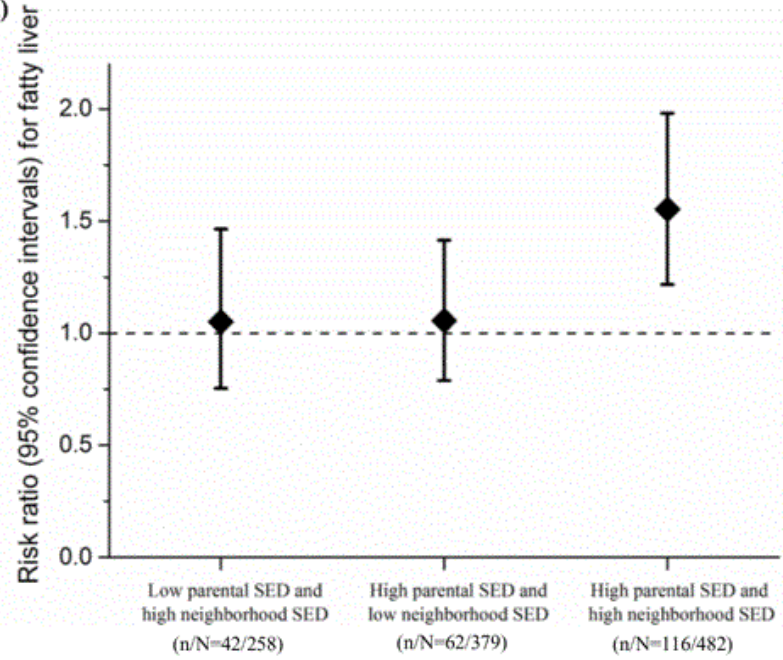

B)

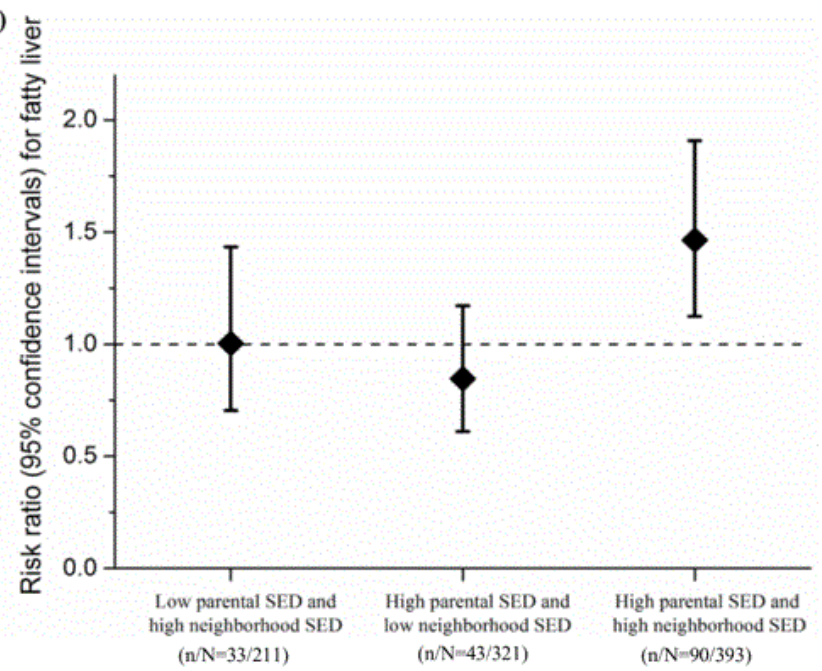

Figure 1.

This article is protected by copyright. All rights reserved. 
Table 1. Relative risk (RR) and $95 \%$ confidence intervals (Cl) of fatty liver in adulthood according to childhood socioeconomic disadvantage (SED)

Cases of $\operatorname{RR}(95 \% \mathrm{Cl})$

fatty liver $n / N(\%)$

Childhood SED

Unadjusted model $\quad$ Adjusted model*

Low

$164 / 1047(15.7)$

1.00 (reference)

1.00 (reference)

High

$221 / 995(22.2)$

$1.42(1.18-1.70)$

$1.33(1.09-1.62)$

$\mathrm{P}=0.0002$

$\mathrm{P}=0.005$

*Adjusted for age, sex, place of birth, and childhood risk factors for fatty liver (body mass index, insulin

[log-transformed], low birth weight). Low birth weight was defined as sex-specific $<10$ percentile (<2850g for girls and <2900g for boys).

Childhood SED is the mean of standardized parental SED and standardized cumulative neighborhood SED from the age of 6 to 21 years. Low childhood SED was defined as $<0$ and high childhood SED as $>0$.

This article is protected by copyright. All rights reserved. 
Table 2. Adulthood pathways (mediators) linking childhood socioeconomic disadvantage with adulthood fatty liver.

\begin{tabular}{|c|c|c|c|c|c|c|c|}
\hline \multirow[b]{2}{*}{ Adulthood mediator } & \multicolumn{2}{|c|}{$\begin{array}{c}\text { Natural direct } \\
\text { effect }\end{array}$} & \multicolumn{2}{|c|}{$\begin{array}{l}\text { Natural indirect effect through } \\
\text { mediator }\end{array}$} & \multicolumn{2}{|c|}{ Total effect } & \multirow{2}{*}{$\begin{array}{c}\begin{array}{c}\text { Proportion mediated of the Tota } \\
\text { effect }\end{array} \\
\% \\
\end{array}$} \\
\hline & $\mathrm{RR}$ & $95 \% \mathrm{Cl}$ & $\mathrm{RR}$ & $95 \% \mathrm{Cl}$ & $\mathrm{RR}$ & $95 \% \mathrm{Cl}$ & \\
\hline Waist circumference & 1.18 & $0.95-1.46$ & 1.12 & $1.06-1.18^{*}$ & 1.32 & $1.06-1.64$ & 45 \\
\hline Body mass index & 1.19 & $0.96-1.47$ & 1.10 & $1.05-1.16^{*}$ & 1.31 & $1.06-1.62$ & 40 \\
\hline Systolic blood pressure & 1.25 & $1.01-1.55$ & 1.08 & $1.04-1.13^{*}$ & 1.36 & $1.10-1.68$ & 29 \\
\hline Insulin & 1.32 & $1.07-1.62$ & 1.02 & $1.00-1.04 *$ & 1.34 & $1.09-1.66$ & 20 \\
\hline Triglycerides & 1.29 & $1.04-1.59$ & 1.04 & $1.01-1.06^{*}$ & 1.33 & $1.08-1.64$ & 14 \\
\hline Physical activity & 1.31 & $1.06-1.63$ & 1.04 & $1.01-1.08 *$ & 1.37 & $1.10-1.70$ & 15 \\
\hline $\begin{array}{l}\text { Red meat } \\
\text { consumption }\end{array}$ & 1.30 & $1.04-1.62$ & 1.02 & $1.00-1.04^{*}$ & 1.32 & $1.06-1.65$ & 7.4 \\
\hline Alcohol consumption & 1.39 & $1.11-1.74$ & 1.00 & $0.99-1.00$ & 1.39 & $1.11-1.74$ & 0.0 \\
\hline Daily smoking & 1.35 & $1.10-1.66$ & 0.99 & 0.98-1.01 & 1.34 & $1.10-1.65$ & 0.0 \\
\hline
\end{tabular}

Mediator indicates the mean value of the variable from the adulthood follow-ups (2001, 2007 and 2011), or daily smoking in any of the adulthood follow-ups. The natural direct effect provides risk ratio (RR) and 95\% Confidence interval (CI) for the association between childhood socioeconomic disadvantage (SED) (high vs low) and fatty liver in a scenario where the level of exposure to the mediator is similar among individuals exposed and non-exposed to high childhood SED. The natural indirect effect refers to the excess risk of fatty liver among those exposed to high childhood SED that is due to the mediating risk in adulthood. In total effect, both natural direct and indirect effects are taken into account to estimate the RR for association between childhood SED and fatty liver. The proportion mediated of the total effect is given as percentages for each mediator. Childhood SED is the mean of standardized parental SED and standardized cumulative neighborhood SED from the age of 6 to 21 years. Low SED was defined as $<0$ and high SED as $>0$ in childhood. The analyses are adjusted for age and sex. ${ }^{*} p<0.05$

This article is protected by copyright. All rights reserved. 


\section{REFERENCES}

1. Chalasani N, Younossi Z, Lavine JE, Diehl AM, Brunt EM, Cusi K, Charlton M, Sanyal AJ. The diagnosis and management of non-alcoholic fatty liver disease: practice Guideline by the American Association for the Study of Liver Diseases, American College of Gastroenterology, and the American Gastroenterological Association. Hepatology. 2012; 55: 2005-2023.

2. Byrne CD, Targher G. NAFLD: a multisystem disease. J Hepatol. 2015; 62: S47-64.

3. Sung KC, Ryu S, Lee JY, Kim JY, Wild SH, Byrne CD. Effect of exercise on the development of new fatty liver and the resolution of existing fatty liver. J Hepatol. 2016;65:791-797.

4. Zelber-Sagi S, Ivancovsky-Wajcman D, Fliss Isakov N, Webb M, Orenstein D, Shibolet O, Kariv R. High red and processed meat consumption is associated with non-alcoholic fatty liver disease and insulin resistance. J Hepatol. 2018;68:1239-1246.

5. Suomela E, Oikonen M, Pitkänen N, Ahola-Olli A, Virtanen J, Parkkola R, Jokinen E, Laitinen T, HutriKähönen N, Kähönen M, Lehtimäki T, Taittonen L, Tossavainen P, Jula A, Loo BM, Mikkilä V, Telama R, Viikari JSA, Juonala M, Raitakari OT. Childhood predictors of adult fatty liver. The Cardiovascular Risk in Young Finns Study. J Hepatol. 2016; 65: 784-790.

6. Mackenbach JP, Stirbu I, Roskam AJ, Schaap MM, Menvielle G, Leinsalu M, Kunst AE; European Union Working Group on Socioeconomic Inequalities in Health.Socioeconomic inequalities in health in 22 European countries. N Engl J Med. 2008;358:2468-81

7. Stringhini S, Carmeli C, Jokela M, Avendaño M, Muennig P, Guida F, Ricceri F, d'Errico A, Barros H, Bochud M, Chadeau-Hyam M, Clavel-Chapelon F, Costa G, Delpierre C, Fraga S, Goldberg M, Giles GG, Krogh V, Kelly-Irving M, Layte R, Lasserre AM, Marmot MG, Preisig M, Shipley MJ, Vollenweider P, Zins M, Kawachi I, Steptoe A, Mackenbach JP, Vineis P, Kivimäki M; LIFEPATH consortium. Socioeconomic 
status and the $25 \times 25$ risk factors as determinants of premature mortality: a multicohort study and meta-analysis of $1 \cdot 7$ million men and women. Lancet. 2017;389:1229-1237

8. Diez Roux AV, Merkin SS, Arnett D, Chambless L, Massing M, Nieto FJ, Sorlie P, Szklo M, Tyroler HA, Watson RL. Neighborhood of residence and incidence of coronary heart disease. N Eng/ J Med. 2001; 345: 99-106.

9. Ludwig J, Sanbonmatsu L, Gennetian L, Adam E, Duncan GJ, Katz LF, Kessler RC, Kling JR, Lindau ST, Whitaker RC, McDade TW. Neighborhoods, obesity, and diabetes--a randomized social experiment. $N$ Engl J Med. 2011; 365: 1509-1519.

10. Kivimäki M, Vahtera J, Tabák AG, Halonen JI, Vineis P, Pentti J, Pahkala K, Rovio S, Viikari J, Kähönen M, Juonala M, Ferrie JE, Stringhini S, Raitakari OT. Neighbourhood socioeconomic disadvantage, risk factors, and diabetes from childhood to middle age in the Young Finns Study: a cohort study. Lancet Public Health. 2018;3(8):e365-e373

11. VanderWeele, T.J. Mediation Analysis: A Practitioner's Guide. Annu Rev Public Health. 2016; 37: p. 17-32.

12. Raitakari OT, Juonala M, Rönnemaa T, Keltikangas-Järvinen L, Räsänen L, Pietikäinen M, HutriKähönen N, Taittonen L, Jokinen E, Marniemi J, Jula A, Telama R, Kähönen M, Lehtimäki T, Åkerblom HK, Viikari JS. Cohort profile: the cardiovascular risk in Young Finns Study. Int J Epidemiol. 2008; 37: 12201226.

13. Suomela E, Oikonen M, Virtanen J, Parkkola R, Jokinen E, Laitinen T, Hutri-Kähönen N, Kähönen M, Lehtimäki T, Taittonen L, Tossavainen P, Jula A, Loo BM, Mikkilä V, Younossi Z, Viikari JS, Juonala M, Raitakari OT. Prevalence and determinants of fatty liver in normal-weight and overweight young adults. The Cardiovascular Risk in Young Finns Study. Ann Med. 2015;47:40-6

14. Vasunta RL, Kesäniemi YA, Ylitalo AS, Ukkola OH. High ambulatory blood pressure values associated with non-alcoholic fatty liver in middle-aged adults . J Hypertens. 2012;30:2015-19 .

This article is protected by copyright. All rights reserved. 
15. Lau K, Lorbeer R, Haring R, Schmidt CO, Wallaschofski H, Nauck M, John U, Baumeister SE, Völzke H. The association between fatty liver disease and blood pressure in a population-based prospective longitudinal study . J Hypertens. 2010;28 : $1829-35$.

16. Browning JD, Szczepaniak LS, Dobbins R, Nuremberg P, Horton JD, Cohen JC, Grundy SM, Hobbs HH . Prevalence of hepatic steatosis in an urban population in the United States: impact of ethnicity . Hepatology. $2004 ; 40: 1387-95$.

17. Lehman BJ, Taylor SE, Kiefe Cl, Seeman TE. Relation of childhood socioeconomic status and family environment to adult metabolic functioning in the CARDIA study. Psychosom Med. 2005; 67: 846-854.

18. Chen H, Burnett RT, Kwong JC, Villeneuve PJ, Goldberg MS, Brook RD, van Donkelaar A, Jerrett M, Martin RV, Brook JR, Copes R. Risk of incident diabetes in relation to long-term exposure to fine particulate matter in Ontario, Canada. Environ Health Perspect. 2013; 121: 804-810.

19. Chen H, Kwong JC, Copes R, Tu K, Villeneuve PJ, van Donkelaar A, Hystad P, Martin RV, Murray BJ, Jessiman B, Wilton AS, Kopp A, Burnett RT. Living near major roads and the incidence of dementia, Parkinson's disease, and multiple sclerosis: a population-based cohort study. Lancet. 2017; 389: 718726.

20. Creatore MI, Glazier RH, Moineddin R, Fazli GS, Johns A, Gozdyra P, Matheson FI, Kaufman-Shriqui V, Rosella LC, Manuel DG, Booth GL. Association of Neighborhood Walkability With Change in Overweight, Obesity, and Diabetes. JAMA. 2016;315:2211-20.

21. Tabaei BP, Rundle AG, Wu WY, Horowitz CR, Mayer V, Sheehan DM, Chamany S. Associations of Residential Socioeconomic, Food, and Built Environments With Glycemic Control in Persons With Diabetes in New York City From 2007-2013. Am J Epidemiol. 2018;187:736-745

22. Theall KP, Shirtcliff EA, Dismukes AR, Wallace M, Drury SS. Association Between Neighborhood Violence and Biological Stress in Children. JAMA Pediatr. 2017; 171: 53-60.

This article is protected by copyright. All rights reserved. 
23. Valeri L, Vanderweele TJ. Mediation analysis allowing for exposure-mediator interactions and causal interpretation: theoretical assumptions and implementation with SAS and SPSS macros. Psychol Methods. 2013;18:137-50

24. Joy D, Thava VR, Scott BB. Diagnosis of fatty liver disease: is biopsy necessary? Eur J Gastroenterol Hepatol. 2003; 15: 539-543.

25. Schwenzer NF, Springer F, Schraml C, Stefan N, Machann J, Schick F. Non-invasive assessment and quantification of liver steatosis by ultrasound, computed tomography and magnetic resonance. J Hepatol. 2009; 51: 433-445.

26. Hernaez R, Lazo M, Bonekamp S, Kamel I, Brancati FL, Guallar E, Clark JM. Diagnostic accuracy and reliability of ultrasonography for the detection of fatty liver: a meta-analysis. Hepatology 2011;54:10821090

27. Kotronen A, Yki-Järvinen H, Männistö S, Saarikoski L, Korpi-Hyövälti E, Oksa H, Saltevo J, Saaristo T, Sundvall J, Tuomilehto J, Peltonen M. Non-alcoholic and alcoholic fatty liver disease - two diseases of affluence associated with the metabolic syndrome and type 2 diabetes: the FIN-D2D survey. BMC Public Health. 2010; $10: 237$

28. European Centre for Disease Prevention and Control. Systematic review on hepatitis B and C prevalence in the EU/EEA. Stockholm: ECDC; 2016.

29. Werner M, Prytz H, Ohlsson B, Almer S, Björnsson E, Bergquist A, Wallerstedt S, SandbergGertzén H, Hultcrantz R, Sangfelt P, Weiland O, Danielsson A. Epidemiology and the initial presentation of autoimmune hepatitis in Sweden: a nationwide study. Scand J Gastroenterol. 2008; 43: 1232-40.

This article is protected by copyright. All rights reserved. 
30. Boberg KM, Aadland E, Jahnsen J, Raknerud N, Stiris M, Bell H. Incidence and prevalence of primary biliary cirrhosis, primary sclerosing cholangitis, and autoimmune hepatitis in a Norwegian population. Scand J Gastroenterol. 1998; 33: 99-103.

31. Nuotio J, Oikonen M, Magnussen CG, Jokinen E, Laitinen T, Hutri-Kähönen N, Kähönen M, Lehtimäki

T, Taittonen L, Tossavainen P, Jula A, Loo BM, Viikari JS, Raitakari OT, Juonala M. Cardiovascular risk factors in 2011 and secular trends since 2007: the Cardiovascular Risk in Young Finns Study. Scand J Public Health. 2014; 42: 563-571.

This article is protected by copyright. All rights reserved. 